\title{
El deseo de matar en la novela y el filme Ensayo de un crimen*
}

Fecha de recepción: 03 de agosto de 2020

Fecha de aprobación: 12 de noviembre de 2020

\section{Resumen}

El tema central de la novela (1944) y de la película (1955) Ensayo de un crimen de Rodolfo Usigli y de Luis Buñuel, respectivamente, es el asesinato artístico. El objetivo de este ensayo es analizar el desplazamiento de las estrategias narrativas de la novela al filme. El contexto recreado en las dos obras es la época posrevolucionaria mexicana. La metodología de análisis para el estudio de las relaciones espacio-temporales, las significaciones y el estilo se establece con base en el concepto cronotopo (tiempo-espacio) de Mijaíl Bajtín y las categorías: orden, duración y frecuencia de Gerard Genette. Los resultados del estudio evidencian, entre otras cosas, que en la película, la representación simbólica de las pulsiones criminales, mediante los objetos, enfatiza el origen psicológico del crimen, atribuido a las relaciones edípicas irresueltas de los personajes. En la novela se puntualiza en que las causas del crimen tienen, también, rasgos de carácter social.

Palabras clave: asesinato artístico, Buñuel, incesto, pulsión de matar, Usigli.

Citar: Soní, Araceli. "El deseo de matar en la novela y el filme Ensayo de un crimen". La Palabra, núm. 40, 2021, e11542. https://doi. org/10.19053/01218530.n40.2021.11542

\section{Araceli Soní Soto}

Doctora en letras modernas, especialidad en hermenéutica y literatura; profesora de licenciatura, maestría y doctorado e investigadora del área "Heurística y hermenéutica del arte" en la Universidad Autónoma Metropolitana-Xochimilco (UAM-X), Ciudad de México. Universidad Autónoma Metropolitana-Xochimilco. Ciudad de México.

aracelisoni93@gamil.com

(ib http://orcid.org/0000-00034840-6547

* Artículo de reflexión.

Realizado a partir del proyecto de investigación colectivo: "Intertextualidad entre el arte y el diseño de la comunicación gráfica" del cual se deriva, "Paratextos gráficos del cine y la literatura" bajo mi responsabilidad. 


\section{Killing Desire in Ensayo de un crimen [The Criminal Life of Archibaldo de la Cruz]}

\section{Abstract:}

Ensayo de un crimen [The Criminal Life of Archibaldo de la Cruz] is an adaptation by Luis Buñuel of the novel with the same title by Rodolfo Usigli. The main of this paper is to examine how narrative strategies move from the novel to the film. The methodology is developed by means of the chronotopes established by M.M. Bakhtin, and also it is organized due the categorization of order, duration, and frequency by Gerard Genette. The result of this study shows that the criminal desire comes from main characters' Oedipal complex. NEvertheless, in the novel it is observed that criminal desire is also arising from social disputes.

Key words: artistic crime, Buñuel, incest, criminal desire, Usigli.

\section{O desejo de matar no romance e no filme Ensaio de um crime}

\section{Resumo}

O tema central do romance (1944) e do filme (1955) Ensaio de um crime é o assassinato artístico. O objetivo deste artigo é analisar o deslocamento de estratégias narrativas do romance ao filme. O contexto recriado nas duas obras é a época pós-revolucionaria mexicana. A metodologia de análise para o estudo das relações espaço-temporais, as significações e o estilo é estabelecida com base no conceito de cronotopo (tempo-espaço) de Mikhail Bakhtin e as categorias: ordem, duração e frequência de Gerard Genette. Os resultados do estudo evidenciam, dentre outras, que no filme, a representação simbólica das pulsões criminais, por meio de objetos, foca a origem psicológica do crime, atribuído às relações edípicas não resolvidas pelas personagens. No romance é apontado que as causas do crime têm, também, caraterísticas de tipo social.

Palavras-chave: assassinato artístico, Buñuel, incesto, pulsão de matar, Usigli. 


\section{Introducción}

La novela Ensayo de un crimen (1944) de Rodolfo Usigli y la película de Luis Buñuel (1955), con el mismo nombre, abordan como tema central el asesinato en cuanto fenómeno artístico. Alrededor de este tópico, se perfilan sus significados con las respectivas diferencias en cada obra. El cineasta transforma el texto de origen de acuerdo con sus intenciones, con su estilo y con los rasgos del medio de expresión cinematográfico, al trasladar las estrategias narrativas de la novela.

El asesinato artístico, tema de los dos productos, amerita una disertación que se desarrolla en la primera parte del presente artículo. Se considera que un crimen es estético si se da a conocer al público y causa en este, efectos conmovedores que afectan su sensibilidad. Sin embargo, un asesinato en cuanto hecho no es artístico, a menos que, se convierta en una creación en la que intervengan la imaginación, las destrezas y un conjunto de criterios formales.

En la novela y en la cinta cinematográfica subyace el deseo de matar como pulsión incontrolable de sus protagonistas: en la primera, ese propósito es artístico y en la segunda, el personaje aspira, también, a ser un gran criminal, aunque se convierta en un asesino potencial. El objetivo de este trabajo es esclarecer la forma específica en que se desplazan las estrategias narrativas de la novela a la película. Para lograrlo, en el segundo apartado, y a partir del punto de vista de Robert Stam sobre la adaptación, se establecen, de acuerdo con Siegfried Kracauer, algunas diferencias entre los lenguajes de los dos medios, cuyo común denominador es su carácter narrativo. La metodología para analizar el tránsito de la obra escrita al filme se basa en el concepto cronotopo (tiempo espacio) de Mijaíl Bajtín. Para profundizar en las relaciones espacio-temporales se adoptan de Gerard Genette tres de sus categorías: orden, duración y frecuencia, con sus respectivas particularidades. Estos conceptos esclarecieron las diferencias de estilo y de sentido en la forma de narrar de cada obra artística, a pesar de su afinidad.

El último apartado se dedica a las representaciones simbólicas de los objetos, dada su relación con las pulsiones criminales de los personajes. Este es un rasgo estilístico de las dos obras, pero, sobre todo, del cine de Buñuel y de la película que se estudia en este artículo. Las cajas de música encarnan el deseo de matar, al representar a la madre con quien los protagonistas preservan una relación edípica. Para concluir se expone una reflexión final. ${ }^{1}$

\section{Lo estético y lo artístico del crimen}

Un crimen es estético si se da a conocer al público y causa en este efectos patéticos y grandes que afectan su sensibilidad. Thomas de Quincey refiere, sin embargo, al asesinato artístico, quien lo distingue de una visión moral; esta interviene cuando el crimen aún no se ejecuta ni se está realizando y si existe un conocimiento previo del mismo (23). Después de

Conviene precisar que lo estético remite a los efectos que experimenta el sujeto ante un acontecimiento o frente al arte. Lo artístico, en cambio, alude a la construcción de una obra en la intervienen las habilidades y los conocimientos formales de quien la realiza, lo cual no significa que los artistas no tengan una experiencia de goce en el proceso creativo. 
consumado, cuando la víctima deja de sufrir y el asesino ha desaparecido, la virtud, dice De Quincey, es innecesaria; entonces «llegó el momento del buen gusto y de las Bellas Artes». Aquí interviene la estética, pues conduce a reconocer que esos hechos moralmente reprobables producen algo meritorio: juzgarse por los preceptos del buen gusto.

De Quincey afirma que los principios de un asesinato artístico, más allá del gusto que puede experimentar el gran público de periódicos que acepta todo lo bastante sangriento, exige mayor sensibilidad (49). Para el autor la «finalidad última del asesinato [...] como una de las bellas artes es [...] la misma que Aristóteles asigna a la tragedia, [...] purificar el corazón mediante la compasión y el terror». En la búsqueda de efectos catárticos, a modo de extirpar los demonios internos, está la explicación del gusto por infinidad de productos culturales que recrean los crímenes más aterradores, la tragedia y el horror. El público los degusta a través de comentarios de sorpresa o rechazo, pero, a la vez, lo alivia y lo saca de su cotidianeidad. La experiencia catártica es una modalidad de la experiencia estética, con la que el receptor comunica, interioriza, asimila y orienta su conducta. Esta experiencia se genera frente al arte y no es otra cosa que el goce de lo bello, ya sean sus temas trágicos o cómicos (Jauss 41-79). ${ }^{2}$

El asesinato en cuanto hecho, no se circunscribe a las representaciones artísticas, tales como la pintura, la música o la literatura, sino a las destrezas del homicida para ejecutar un crimen fuera de los cánones comunes. Quizá por esto, De Quincey excluye del asesinato artístico los producidos por robo, los ejecutados a personajes públicos, debido a que la ubicuidad virtual de estos últimos los convierte en ideas abstractas ${ }^{3}$ (49). Se trata de un crimen gratuito, cuyo fin es la grandeza y la perfección del acto, tal y como lo pretende el protagonista de la novela Ensayo de un crimen de Usigli. Un asesinato muy sanguinario satisface a la mayoría, pero un artista posee gustos depurados. En cuanto al momento y el lugar, el autor opina que para el sentido común es más propicia la noche y la discreción en callejones oscuros. Sin embargo, estas normas se han violado y los resultados han sido felices (De Quincey 50-51).

La fascinación por el crimen es un reflejo de la época romántica en el siglo xix, pero el primer antecedente teórico al respecto se debe a Lessing en 1766, al incursionar en la representación artística de lo repulsivo ${ }^{4}$. Casi un siglo después, en 1853, Karl Rosenkranz (1992) escribe un texto decisivo: Estética de lo feo, en el que refiere a lo repugnante, a lo horrendo, al crimen y a conceptos afines. Muchos pensadores románticos y prerrománticos redimensionan estos valores. Se redescubre a Longino de la época helénica: lo bello se aparta de las reglas que lo definen y se concentra en los efectos que produce. El punto culminante de estas inquietudes se vierte en lo sublime: aquello que por su majestuosa belleza o fealdad conmociona los sentidos. Edmund Burke escribe sobre el tema desde 1757 y distingue dos perspectivas: la del sujeto que recibe la impresión causada por el objeto y las cualidades de

2 Las tres modalidades de la experiencia estética son: la poiesis o creación artística; la aisthesis, recepción o percepción de la obra; la catarsis arriba explicada.

3 Debe considerarse también un tipo de persona que se adapte a los propósitos del asesino, el sito del evento, el momento adecuado y algunos detalles más.

4 Lessing (2015) estudia la escultura Laocoonte (s. i a. de C.), la cual representa a un sacerdote troyano y a sus hijos devorados por dos horribles serpientes enviadas por Minerva. La escultura se basa en el relato de Virgilio, libro segundo de la Eneida. 
este, que lo determina como bello o sublime, placentero o doloroso (15). Observemos que estas aportaciones se encauzan a la representación artística y no a los hechos criminales y horrendos.

Las primeras reflexiones sobre el tema no aluden a los efectos del arte, sino a la reacción ante los fenómenos naturales. Immanuel $\mathrm{Kant}^{5}$ realiza aportes fundamentales al respecto $\mathrm{y}$, a diferencia de Burke, se concentra en los efectos del espectador. Para él, lo sublime es una disposición del espíritu en el sujeto, capaz de captar una dimensión de grandeza en la imaginación por encima del juicio sobre lo bello y su concepto de finalidad; incluye, además, un sistema de leyes para valorar al objeto. Kant afirma que lo sublime es el efecto de magnitud proveniente del espíritu que excede toda medida de los sentidos y no una simple estimación estética (125). Al igual que Burke, Kant asume que lo sublime no solo se produce frente al arte, sino ante la naturaleza, y aunque enfatiza en la vivencia del sujeto, se infiere que se origina a partir de la obra o el fenómeno natural.

Por otra parte, Georg W. F. Hegel piensa que, a diferencia del arte clásico, en el romántico se encuentran todas las manifestaciones de la vida, todo lo que hay de grande y de mezquino, de más elevado y de más bajo (170). Pero, la exaltación romántica más apasionada de lo feo la realiza el escritor romántico Víctor Hugo (1967), en el prefacio a su obra teatral Cromwell; texto que alcanzó el nombre de manifiesto del romanticismo. En este refiere a lo grotesco como: algo horrible, repelente, deforme que se convierte en bello.

Avanzado el siglo xix, entre 1871 y 1872, Friedrich Nietzsche estudia la génesis del mito trágico y piensa que, si bien los griegos compartían el placer por la visión de la apariencia bella, relegaron esta embriaguez y encontraron una satisfacción aún más alta en la aniquilación del mundo visible: en el sufrimiento por el destino del héroe, en el dolor; en términos estéticos, en el goce por lo feo, dentro de lo cual se halla el crimen (226-228). Nietzsche escribe que el arte no es solo una imitación de la realidad, sino un suplemento metafísico que la supera y la transfigura; el placer estético que genera trae consigo, a veces, un deleite moral en forma de compasión o de triunfo. No obstante, la exigencia del mito trágico es la búsqueda del placer en la esfera estética pura, sin invadir el terreno de la compasión, del miedo y de lo moralmente sublime. Nietzsche se pregunta: ¿cómo lo feo y lo desarmónico suscitan el valor estético? y responde que estos justifican la existencia y el mundo, pues incluso participan en el placer. En sí, el mito trágico tiene sus raíces en el pesimismo, en el deseo de dar imagen a todas las cosas terribles y funestas de la existencia; fenómeno que explica en la actualidad, el gusto del público por la enorme producción cultural que incluye los crímenes más aterradores.

Lo anterior puede justificar por qué el asesinato puede considerarse un arte, tal y como dice De Quincey, cuyos efectos patéticos generan fruición en un público ávido de representaciones sangrientas. Sin embargo, el arte es una representación, una recreación de acontecimientos vividos, vistos o contados por otros al artista, en la que intervienen la imaginación,

Kant escribe en 1764, Lo bello y lo sublime. Fundamentación de la metafisica de las costumbres y veintiséis años después, La crítica del juicio, en la que también habla sobre el tema. 
las destrezas y un conjunto de criterios formales. Por esto, precisemos que un asesinato, en cuanto hecho, no es aún una representación ni una recreación; pasa a serlo en la crónica periodística u oral, en una novela, en una película. En consecuencia, el impacto, la apreciación del público, es decir, la experiencia estética tiene lugar con relación a lo que se narra y a la forma de hacerlo.

Quizá por esto, De Quincey atribuye a la moral y no al arte, el antes y el momento en que ocurre el asesinato, pues el crimen como tal, no es una representación artística. El asesinato conmociona los sentidos, produce efectos estéticos, pero solo es recreación artística al trasladarse a una obra y si cumple con determinados requisitos formales. Tal y como dice Nietzsche, el arte no es una imitación de la realidad, sino una transformación de la misma y, solo en los géneros artísticos, los hechos reales o sus indicios se transfiguran. A un asesinato se le pueden atribuir determinadas cualidades artísticas: su perfecta planeación, el cuidado de su ejecución, el espíritu refinado de sus intenciones, sin que sean representaciones al modo de las tragedias griegas. En la novela y en la película Ensayo de un crimen, los personajes principales, más aún en la novela, ponen en práctica esas cualidades, conciben el asesinato como un arte, aunque el público sepa que está frente a dos obras de ficción, que proponen una disertación sobre el crimen, cuyo fin es el disfrute y la reflexión.

\section{Confluencias y divergencias entre la novela y el cine}

La puesta en escena de la película Ensayo de un crimen constituye una traslación de las estrategias narrativas de la obra escrita. Cada medio se expresa con sus lenguajes, sus reglas, sus materiales, sus técnicas y existen algunas diferencias notables entre la novela y el cine, a pesar de que ambos sean relatos. Kracauer afirma que, la novela es más apta para recrear la vida interior de los personajes, en tanto que, el cine facilita la representación de la realidad externa, captada por la cámara (297). Para incursionar en las introspecciones de los personajes, el cine suele recurrir al monólogo o a la voz en off; solo que estos recursos no son propios de este medio y demeritan su calidad cinemática. La vida íntima de los personajes se representa en un filme con sus acciones, su apariencia física, su lenguaje corporal, sus gestos faciales y por los diálogos. De aquí, la aseveración de Kracauer respecto a que el cine representa la realidad visible.

El concepto cronotopo (espacio-tiempo) de Mijaíl Bajtín, contribuye a esclarecer el tránsito de la novela al cine y, aunque el autor lo estudia en la novela, aclara que se extiende a otros géneros artísticos. Se define como la conexión esencial de relaciones temporales y espaciales asimiladas artísticamente en la literatura. Esta categoría incide en la forma y el contenido de la obra; en esta, el tiempo se condensa con relación al tiempo real y el espacio penetra en el movimiento del tiempo, es decir, en el transcurrir de la historia (249). El cronotopo de una novela, en su paso a una película, se altera, pues la forma (determinada por el medio de expresión) se articula con el contenido en tiempos y espacios distintos.

Muchas dudas sobre el traslado de la novela al cine se vinculan con los cambios en la fábula; esto es, con las modificaciones de los contenidos narrativos. Tres de las principales 
categorías de las investigaciones de Gerard Genette sobre la narración se pueden emplear para el análisis de las relaciones espacio temporales: el orden, la duración y la frecuencia. Indudablemente, los lugares ubicados en un tiempo determinado repercuten en la construcción artística de los significados (81).

Genette parte de que todo relato es una secuencia dos veces temporal: el tiempo de los sucesos que se cuentan (la historia) y el de lo que aparece en el relato (lo narrado): «tres años de la vida del héroe resumidos en dos frases de una novela, o en algunos planos de un montaje». La primera categoría, la de orden, confronta la disposición de los acontecimientos en la narración con los de la historia. Los relatos, novelescos o cinematográficas, recurren a lo que el autor nombra anacronías o "formas de discordancia temporal" que articulan la secuencia de los sucesos (89). Estas pueden presentarse de dos maneras: como prolepsis, para evocar por adelantado un acontecimiento posterior al presente de la historia. Las otras, las analepsis, refieren a acontecimientos anteriores a ese presente (Genette 91-95) ${ }^{6}$. Si la distancia temporal, ya sea hacia el pasado o hacia el porvenir, se encuentra más o menos lejos del momento en que se interrumpe el relato se produce lo que el autor nombra alcance de la anacronía y si ese suceso abarca una duración larga la llama amplitud de la misma (Genette 103)7.

La segunda categoría, según Genette, es la de duración; esta incluye, además del tiempo, el espacio. Se refiere a la constancia de velocidad: el vínculo entre una medida temporal y una espacial (tantos metros por segundo o viceversa). El autor afirma: «la velocidad del relato se definirá por la relación entre -la de la historia- medida en segundos, minutos, horas, días [...], y una longitud -la del texto- medida en líneas o en páginas» o bien en secuencias o escenas en el filme; lo cual se relaciona con el ritmo del relato (145). La tercera y última categoría temporal es la de frecuencia o repetición: la recurrencia de un acontecimiento o una serie de estos, ya sean semejantes o considerados por su semejanza (Genette 172-173). Lo antes descrito se empleará para establecer las discrepancias entre la novela y la película, sobre todo, en correspondencia con el crimen. Tales diferencias obedecen, por un lado, al lenguaje de cada medio de expresión y, por el otro, a las ideas de Buñuel, quien modificó el texto de origen de acuerdo con sus propósitos y su estilo.

Rodolfo Usigli publicó Ensayo de un crimen en 1944. La historia gira en torno a las introspecciones del personaje principal, Roberto de la Cruz, respecto a una obsesión: convertirse en un célebre criminal. El cronotopo de la obra se configura mediante la recreación de los sitios urbanos de la Ciudad de México, la de los paisajes de su zona del centro: sus restaurantes, sus cafés, sus bares, sus monumentos, sus edificios emblemáticos, sus parques, tales como la Alameda, Chapultepec; sus calles, así como lo que ocurre en ellas. Estos espacios se articulan con el tiempo: la época posrevolucionaria, cuyo trasfondo tiene otro tema no menos importante: las costumbres de la clase burguesa que, entre otras cosas, posee gustos refinados. Once años después, en 1955, Buñuel realiza la película con el mismo nombre en la

Genette establece algunas modalidades de analepsis y prolepsis, según la manera en que los relatos manejen el tiempo.

El autor ejemplifica estos conceptos con un pasaje de la Odisea: Homero, en el canto xix, evoca el tiempo en que Ulises adolescente recibió una herida, cuya cicatriz lleva aún en el momento en que Euriclea se dispone a lavarle los pies. Esta analepsis tiene un alcance de varias decenas de años y una amplitud de unos días (Genette, 103-104). 
que, de alguna manera, se ciñe a los mismos contenidos ${ }^{8}$. El tiempo y los espacios en ambos productos son equivalentes, como dice Robert Stam «cada texto puede generar una infinidad de lecturas, cualquier novela puede generar infinidad de adaptaciones que son inevitablemente parciales y personales, y que se apoyan en conjeturas e intereses muy definidos» ${ }^{9}(68)$. En el cine, según Stam, el cronotopo establece conexiones en tres elementos: a) el decorado en lugares como bares, interiores, calles; b) articulaciones temporales como la lentitud o rapidez deliberada; c) articulaciones espaciales como perspectivas o ángulos (72). Estos elementos ubican el tiempo, determinan el espacio en la película y se pueden equipar con los de la novela, cuya expresión se produce mediante el lenguaje verbal. Si en la novela, el tiempo se condensa con relación al tiempo real, en la película, se comprime aún más; además, los lugares se convierten en algo visible y se imbrican con su temporalidad en el desarrollo diegético.

El eje de los dos productos es el asesinato, aunque en la novela la idea artística del mismo es más enfática; su narrador omnisciente facilita la recreación de los pensamientos y sentimientos del personaje, quien adjetiva sus propósitos asesinos como artísticos. Por las diferencias entre la novela y el cine, las imágenes de la cinta muestran esas reflexiones con la expresión del rostro, de los gestos, de las actitudes y de la actuación. El espectador las interpretará con la ayuda de su imaginación y con los recursos del cine: el uso de primeros y primerísimos primeros planos, planos medios y americanos. Estos rasgos del medio de expresión y algunos cambios en la fábula conducen a una primordial diferencia: el asesino en el filme siempre es potencial, en la novela, uno de los intentos se concluye.

La recreación de los espacios urbanos, referidos en la obra escrita, se restringe en el filme. Pese a que el lenguaje del cine favorece las imágen es de exteriores como las calles, los parques, los restaurantes en la película de Buñuel dominan las escenas en interiores (Kracauer 297). Lo que en muchas películas responde al presupuesto, en este caso, se atribuye a las intenciones de Buñuel, dada su predilección por los temas psicológicos. Aquí, el cronotopo de la novela se altera al pasar a la cinta, pues el espacio interior incide en los giros de sentido que proyecta el filme.

La representación psicosocial de la sociedad burguesa mexicana posrevolucionaria de la obra escrita, en el filme es análoga; las dos historias (novela y filme) se ubican en el mismo contexto sociohistórico. La relación espacio temporal es equivalente; en ambos casos, se recurre a lo que Genette nombra alcance de la anacronía, pues emplean una analepsis distante

$8 \quad$ El cineasta comienza el guión con Usigli y lo concluye con Eduardo Ugarte por algunos desacuerdos con el novelista. Realizado el filme, Usigli demandó a la productora Alianza Cinematográfica, a Ernesto Alonso (dueño de los derechos) y a los guionistas por trastocar los contenidos de su obra. La demanda no prosperó, ya que en los créditos se incluyó la leyenda "inspirada en" la novela. Usigli logró que fuera de México la cinta llevara el nombre La vida criminal de Archibaldo de la Cruz (Herrera, 2015: 228). Los nombres de los personajes principales de la novela se conservan en el filme, con la diferencia de Archibaldo de la Cruz en lugar de Roberto. Los actores importantes son Ernesto Alonso (personaje principal), Patricia Terrazas (Rita Macedo), Lavinia (Miroslava Stern), Carlota (Ariadna Welter).

$9 \quad$ Al respecto de lo que dice Stam, en la película Ensayo de un crimen se suprimen importantes componentes y largos pasajes de la novela, por ejemplo: toda la historia relacionada con el conde Schwartzemberg y la participación del exinspector Valentín Herrera, quien funge como una especie de psicoanalista, entre otros aspectos de menor importancia. Buñuel, en cambio, incorpora a una monja como una de las potenciales víctima de los intentos de asesinato del protagonista. Con esto el cineasta reitera una de las características de su estilo. 
al punto en que se interrumpe la narración: retroceden a la época revolucionaria mexicana, para volver al presente posrevolucionario.

Los rasgos psicológicos de los personajes principales difieren. Ambos evidencian impulsos criminales, aunque la planeación detallada y premeditada de los crímenes se enfatiza en la novela. Las reflexiones internas y obsesivas en torno al asesinato artístico, como fin último y objeto de la vida de Roberto, son un rasgo más propicio para la novela. En la cinta, la personalidad de Archibaldo es más extrovertida: revela a la que será su esposa su fantasía de ser "un gran santo o un gran criminal", así como su deseo de salvarse mediante el matrimonio. Esto en la novela, Roberto no lo exterioriza; aunque lo piensa y contraiga matrimonio después de sus fallidos intentos. En la cinta, las tentativas de asesinato son menos planeadas, más inmediatas; circunstancias imprevistas impiden su ejecución. Mientras en la obra de origen, el azar y el destino, en un sentido más amplio, determinan los actos del protagonista. Aquí, la velocidad de la película, su ritmo, es más rápido: por un lado, porque se comprimen en una hora y treinta y dos minutos los contenidos de 302 páginas de la novela y porque el carácter fársico-melodramático del filme cambia el tono serio de la obra escrita ${ }^{10}$ (Genette 145).

Otra discrepancia psicológica es la sensación de fracaso. Las introspecciones de Roberto en la novela dejan al descubierto una gran desilusión en cada ocasión que se frustra su fantasía criminal: ocurre con Patricia Terrazas y con el conde Schwartzemberg ${ }^{11}$. El personaje mata a su esposa creyendo que era su amiga Lavinia, hecho que también reviste fracaso, pues la policía lo califica como pasional, en tanto que su ideal del crimen "artístico" excluía los celos. Aquí entra en juego la tercera y última categoría de Genette: la frecuencia o repetición (172-173) de los intentos y fantasías de asesinato, cuya función es acentuar la sensación de fracaso y la pulsión criminal del protagonista. En el filme, los intentos criminales de Archibaldo también se repiten, pero nunca se concluyen, las imágenes no revelan emociones de frustración. La insistencia de hechos fortuitos que ocurren en cada ocasión que intenta asesinar y sus fantasías al respecto enfatizan el carácter fársico-melodramático de la cinta. En ninguno de los dos casos se asocian los crímenes a intereses económicos; de aquí su afinidad con el crimen artístico, según se explicó.

Para revelar el origen de la obsesión criminal de los dos personajes se recurre a una analepsis de alcance: ambos relatos regresan a la infancia de los protagonistas, a la época revolucionaria. En la novela, Roberto, a sus ocho o nueve años, es testigo del asesinato violento y arbitrario de un anciano, ejecutado por el militar que lo llevaba al parque. En la cinta, la institutriz de Archibaldo muere en su presencia, por un balazo que llega a la ventana desde la calle. Ambos acontecimientos se relacionan con el vals El príncipe rojo de Waldteufel: en la novela, lo toca en la calle un organillero mientras ocurre el asesinato; en el filme, es

10 Xavier Robles, quien estudia los géneros cinematográficos, dice que Ensayo de un crimen es fársico-melodramático. La farsa tiene un carácter irreverente, violento, transgresor, subversivo y poético. El melodrama, por otra parte, subvierte la realidad exaltando las pasiones humanas, la purificación de las mismas y la redención de la culpa (2014, 145-149). Muchos de estos rasgos se encuentran en la película.

11 La frustración del protagonista se observa en varios pasajes. Al enterarse del incendio en el que murió el conde dice, por ejemplo: «Nadie sabría ya que el conde había sido asesinado, nadie sentiría ya la justicia humana y poética que había en la muerte del odioso hombre de sebo» (Usigli, 2018, 201). 
la melodía de la caja de música que Archibaldo escucha cuando la institutriz cae fulminada. Archibaldo niño fantasea con la muerte de la institutriz, influenciado por el cuento que la niñera le relata momentos antes de morir, en el cual, la caja posee poderes mágicos. El niño imagina que es el asesino al fantasear con su muerte ${ }^{12}$. Estas analepsis son fundamentales para explicar el origen de las obsesiones criminales de los protagonistas. Sin embargo, en la novela el anonimato de la víctima y la alevosía del militar proyectan mayor indignación debido a la injusticia del hecho. En el filme, la muerte de la institutriz es producto tanto del contexto social como del azar, además de mostrar las perversiones del infante.

El vals El príncipe rojo es el leitmotiv que detona las pulsiones criminales de los protagonistas en su vida adulta. Cuando lo escuchan o lo recuerdan surgen de inmediato sus deseos de matar. En la novela, la caja de música que toca el vals la adquiere el personaje en un anticuario y no es la misma que tuvo en su infancia; su interés radica en lo que su música simboliza. En la cinta, Archibaldo adquiere por azar la misma caja que perteneció a su madre en una tienda de antigüedades; lo cual acentúa el vínculo materno del personaje. Este objeto simbólico se inscribe en el cronotopo de las dos obras, como un elemento importante de los antiguos decorados burgueses de la época, que la película exhibe mediante planos generales y medios, mientras la obra escrita los describe.

Según Genette todo relato implica un acto de narrar, ejecutado por el sujeto de enunciación. (81). En la novela el narrador omnisciente cuenta los sucesos en forma lineal: del presente narrativo retrocede con pequeñas analepsis a las memorias de infancia del protagonista hasta el desenlace. El filme también comienza en presente: el acto narrativo se produce con imágenes y con la voz en off del personaje. En este momento narra sus experiencias infantiles a la monja que funge como enfermera en el hospital, donde se encuentra, mientras en pantalla se hojea un libro de fotos de la Revolución. Después de la analepsis, la narración vuelve al presente. A partir de aquí, una larga retrospectiva cuenta la historia de vida del personaje, hasta regresar a una escena anterior al final; es decir, la estructura del filme es circular, pero antes del desenlace.

Los finales de las dos historias son esperanzadores, más aún el del filme: Archibaldo, después de su entrevista con el juez, regresa a su casa, pone en un saco la caja de música, se dirige, al parecer, al lago de Chapultepec y la arroja. Tal acontecimiento simboliza la abolición de su pasado y de un prometedor futuro: avanza por el bosque y se reencuentra con Lavinia, su amiga. Los personajes caminan hacia adelante, de espaldas a la cámara y por la vereda del bosque; frente a ellos, un plano general con altos árboles a los lados del camino proyecta el horizonte. En la novela, Roberto acaba en el manicomio; sin embargo, el ex inspector Herrera, le dice que saldrá más o menos pronto, cuando los médicos crean curarlo de su locura y que Lavinia desea visitarlo.

12 El deseo infantil se reproduce en repetidas ocasiones en su edad adulta, lo cual enfatiza las cualidades psicológicas de los personajes de Buñuel. 


\section{Símbolos en la novela y en la película}

Este análisis se concentra en el significado simbólico de los objetos en relación con las pulsiones criminales, sobre todo, en la película; esos objetos se inscriben en el tiempo y el espacio de las obras. El cine de Buñuel, fiel a su herencia surrealista, abandona su función utilitaria, para simbolizar su impenetrabilidad pulsional. Kracauer afirma que el cine recrea la realidad física, visible y que, a través de ella, se proyectan emociones, sin embargo, también representa pulsiones (2015). No me refiero a lo que denota el primerísimo primer plano de los ojos de Archibaldo antes de ejecutar su plan contra Patricia Terrazas, por ejemplo, sino a la connotación de estímulo que siente el personaje cuando se corta al afeitarse y derrama sangre $^{13}$. Los objetos en el cine de Buñuel constituyen signos subversivos que develan las pulsiones ocultas. Quizá por esto, Pier Paolo Pasolini (citado en Monegal 157) atribuye al lenguaje cinematográfico un potencial poético: es objetivo en su representación, pero al carecer de significados predeterminados es, asimismo, subjetivo.

El cine de Buñel recurre de manera constante a múltiples objetos: cajas, cuerdas, manzanas, pistolas, sacos, pianos, zapatos, bastones, navajas, campanas, entre otros; los cuales, generalmente, son símbolos de contenidos pulsionales. Las cajas, los cajones, las habitaciones y otros de este género encierran algo obscuro: en Un chien andalou ${ }^{14}$ uno de los personajes sujeta a su estómago una caja enigmática; en Belle de jour ${ }^{15}$ una caja emite un sonido que excita a la protagonista; en El ángel exterminador (1962) una caja contiene estupefacientes; en Cet obscur objet du désir ${ }^{16_{2}}$ el personaje coloca una caja entre las piernas de la protagonista que en el contexto sustituye su sexo. Las cajas, los bastones, las navajas -en la novela y el filme Ensayo de un crimen-, al igual que el zapato negro, el vaso de leche, el maniquí y su pierna en la película, tienen connotaciones sexuales y son símbolos de la conducta criminal de los protagonistas.

El símbolo más sobresaliente en las dos obras es el vals El príncipe rojo encarnado en la caja de música. En la novela ese vals proviene del organillero, cuando el militar asesina al anciano y, aunque no lo emite una caja, las cajas fueron objetos significativos durante la adolescencia de Roberto. Por esto, cuando encuentra una caja con la música de sus invocaciones, la compra. En la cinta, Archibaldo adquiere la misma caja musical que perteneció a su madre, pues el objeto lo remite a la trágica muerte de su institutriz en su infancia. Las cajas y su música se asocian al deseo y al asesinato de manera metonímica ${ }^{17}$ : al deseo reprimido de fundirse con la madre y a los asesinatos, que desembocan en el deseo de matar de los protagonistas. La represión incestuosa se sustituyó por pulsiones perversas ${ }^{18}$, no por la sexualidad con otras mujeres como suele ocurrir, pues ni la película ni la novela dan cuenta

13 Esta es una escena representativa de varios fragmentos de la novela en los que las pulsiones invaden al protagonista: «sintió como si su cabeza, un momento cercenada y puesta a flotar en una atmósfera de bárbaro calor, volviera a quedar ajustada sobre sus hombros» (Usigli, 2018, 11).

Un perro andaluz (1929).

Bella de día (1967), aunque en la traducción al español la nombran Flor de día.

Ese obscuro objeto del deseo (1977).

17 Esta figura consiste en asignar a una cosa el nombre de otra, con la que existe una relación de contigüidad espacial, temporal o lógica. En la novela y en la película, la caja adopta el lugar de la madre.

18 La irresolución del incesto puede sublimarse hacia otros ámbitos como pudiera ser la creación artística. 
de experiencias sexuales de los protagonistas. Sigmund Freud menciona que «los estuches, cajas, cajones $[\ldots]$ corresponden al cuerpo femenino, como [...] toda clase de recipientes» (192). En la novela y el filme, ese cuerpo es el de la madre de los personajes en la casa-caja materna. Horst Kurnitzky, basado en Freud, afirma que en el complejo de Edipo «se reconocen las bases de la neurosis como expresión del dominio fracasado de los deseos pulsionales, más exactamente incestuosos» (124), cuando éstos no se subliman ocasionan enfermedades neuróticas. Por ello, la relación con otras mujeres como sustituto de la madre es el camino para evitar el mismo destino de Edipo (124- 125). De aquí que, los protagonistas vean en el matrimonio, su salvación; única manera de sublimar su sexualidad reprimida en una sociedad regulada.

La obsesión de Buñuel por la representación de la represión sexual, las relaciones perversas y la crítica eclesiástica provienen de su educación burguesa y religiosa ${ }^{19}$. Durante su infancia y su adolescencia «la religión era omnipresente, se manifestaba en todos los detalles de la vida» (Buñuel 23). En su libro autobiográfico, Mi último suspiro (2012), alude a la tiranía sexual que padeció y a la idea inculcada sobre la castidad como la más excelsa de las virtudes. Esto confirma que la caja y su música simbolizan un vínculo incestuoso irresuelto que desemboca en las pulsiones criminales del protagonista de Ensayo de un crimen, ya que al desprenderse de la caja es incapaz de matar, incluso, a un saltamontes. Este significado se acentúa aún más al introducir la caja en un saco para tirarla. Freud dice al respecto: «el equipaje con el que viajamos es la carga de pecados que nos abruma» pues al tirar la valija al agua con la caja adentro, el protagonista arroja sus cargas (189) . Liberado de ellas, se halla en la posibilidad de establecer una relación con Lavinia al margen de sus perversiones ${ }^{20}$. En esta secuencia, Archibaldo se desprende de su bastón, cuya connotación fálica, en este contexto, significa abolir su impotencia, al deshacerse de lo que hasta ese momento representó una imposibilidad. En la novela, la caja pasa a formar parte del decorado en la casa del reciente matrimonio entre el protagonista y Carlota; aunque al final y después del homicidio, aparece rota. Antes de romperse, su poder evocativo respecto al crimen permanece latente. Por eso, al quedar al alcance de Carlota, ésta la activa sin saber las consecuencias, pues detona las pulsiones de Archibaldo, quien la mata.

Las connotaciones sexuales en el filme son muy evidentes, las víctimas son siempre mujeres deseables: la imagen muestra las piernas atractivas de la institutriz en primer plano; Patricia Terrazas es joven y deseable, a diferencia de la novela; Lavinia es una mujer cautivadora para el personaje; Carlota es la elegida para ser esposa; incluso, la monja sugiere erotis$\mathrm{mo}^{21}$. En la novela, las víctimas son indeseables, Roberto tiene motivaciones similares a las de Raskólnikov de Crimen y Castigo de Fiódor Dostoievski. Los dos personajes (Roberto y Raskólnikov) se atormentan con sus obsesiones; a diferencia de Archibaldo, en la cinta, estos piensan que hay seres que no merecen vivir por su personalidad antiestética o desagradable.

19 Durante sus primeros años en la provincia de Zaragoza, España, su familia le inculcó una fe ciega y lo ingresó a colegios jesuitas.

$20 \quad$ El saco aparece en películas como La mort en ce jardin (1956), Nazarín (1959) y Cet obscur objet du desir (Ese oscuro objeto del deseo, 1977), con las mismas connotaciones de carga emocional.

21 El que las monjas sean mujeres deseables en el cine de Buñuel, se observa con claridad en Viridiana (1961). 
El asesinato de la esposa, por el protagonista, no responde a esta idea, al constituir un acto impulsivo y por equivocación.

El erotismo es otro elemento relacionado con las pulsiones perversas, evidente sobre todo, en la película y alrededor de Archibaldo y Lavinia. El erotismo es la sexualidad transfigurada, es una metáfora en la que interviene la imaginación y, mientras la sexualidad está al servicio de la procreación, el erotismo es el placer en sí mismo ( $\mathrm{Paz} 10)^{22}$. El matrimonio, institución que regula la sexualidad con fines de procreación, es a lo que socialmente aspiran los personajes en su ambiente burgués y religioso, en el cual el placer sexual, fuera del matrimonio, se vive como pecado. Lavinia se sale de estos parámetros, no es candidata para el matrimonio dado su estatus social y no representa la pureza. En la película este personaje trabaja para mantener su independencia y no reza ante un altar como Carlota. De aquí que, la erotización y la proyección del deseo en los objetos se produzca en torno a la relación de Archibaldo con ella. El maniquí que representa la persona Lavinia, su copia, la proyecta como cosa en la que el personaje canaliza su deseo perverso. La desea como objeto ante su incapacidad de poseerla como sujeto, dada la irresolución incestuosa con la madre. Anhela matar a la mujer que sustituye a su madre, por quien el protagonista puede experimentar amor y rechazo. Ante la imposibilidad, atenta contra el maniquí para deshacerse simbólicamente de la rival de su madre y preservar su vínculo incestuoso. El juego erótico se evidencia mediante el intercambio de roles entre el objeto (maniquí) y la persona Lavinia, que interactúan con el protagonista: Archibaldo compra ropa para la muñeca y goza al manipularla; acaricia al maniquí y el seno de este; Lavinia le pega como si se lo hiciera a ella. Esta intercambia su ropa con la de su réplica y Archibaldo levanta su falda para ver sus prendas íntimas; besa a la maniquí, ante el rechazo de Lavinia y besa después a ésta; asimismo, la mujer coloca un sostén sobre su blusa para cerciorarse de que corresponde a su talla. Finalmente, se pone la ropa nueva destinada a la muñeca. Las ropas constituyen fetiches que refuerzan el contenido erótico, al incentivar la fantasía ${ }^{23}$.

Antonio Monegal estudia el discurso figural de Buñuel y dice que el maniquí es una metáfora al sustituir a la persona, mientras otros objetos como la pierna suelta y el zapato de la muñeca son sinécdoque ${ }^{24}$ y metonimia respectivamente (167-170). Sin duda lo son, aunque todas estas figuras son símbolos de una representación erótica perversa, en tanto preámbulo de un propósito asesino y no de un encuentro sexual. La llegada de los turistas, a quienes Lavinia citó para mostrarles la casa de Archibaldo, sin que este lo supiera, inhibe su plan. La protagonista, a punto de salir de la casa con los turistas y satisfecha de su juego al frustrar las intenciones sexuales de Archibaldo, según creía, le dice: «puede consolarse con mi hermanita» (el maniquí). A solas con el maniquí, Archibaldo lo arrastra hacia el horno de objetos ce-

22 Octavio Paz (2005, 10-11) establece una similitud entre el erotismo y la poesía y dice: su relación «es tal, que puede decirse, sin afectación, que el primero es una poética corporal y que la segunda es una erótica verbal», así como el lenguaje en la poesía se desvincula de su fin natural: la comunicación, en el erotismo las tendencias de la sexualidad se emancipan de la procreación.

23 Buñuel, en sus memorias $(2012,308)$, manifiesta su interés por el fetichismo. Dice que en Belle de jour describe con bastante fidelidad varios casos de perversiones sexuales, perceptibles desde la primera escena de la película $E l$, pero advierte que sus intereses son teóricos y exteriores, pues su sexualidad no es perversa.

24 Figura retórica que designa una cosa con el nombre de otra con la que existe una relación de inclusión, el nombre del todo por la parte o la parte por el todo. 
rámicos y lo quema, mata simbólicamente a su víctima, al sustituto de su madre, a la rival de esta, y mantiene vigente el vínculo incestuoso. Durante el arrastre se desprende la pierna del maniquí (sinécdoque): la pierna que remite a la muñeca, un objeto desprendido de otro, un miembro mutilado del cuerpo, según (Monegal 171), que Archibaldo une a la muñeca antes de quemarla. Se desprende, también, el zapato de la otra pierna y en seguida el protagonista recibe la visita imprevista de Carlota, acompañada de su madre para manifestarle su aceptación ante su previa petición de matrimonio. Durante esta escena Archibaldo ve el zapato y lo esconde abajo del sofá para evitar que sus visitantes lo vean. El zapato, símbolo sexual del genital femenino, en cuanto hueco en el que se introduce el falo (el pie), se une al conjunto de fetiches de connotación sexual y erótica perversa.

El significado erótico de los zapatos, siempre negros, se repite en otras películas de Buñue ${ }^{25}$. En Le journal d'une femme de chambre ${ }^{26}$, un rico burgués mira con lascivia los pies de la protagonista, quien a petición de aquel se pone unos zapatos negros de tacón; los zapatos en esta escena son claros fetiches eróticos y perversos. En Belle de Jour mediante un close up, la cámara enfoca los pies calzados de la protagonista al subir los peldaños hacia el burdel donde trabajará. En El (1953), Francisco se trastorna al mirar los zapatos negros de Gloria al interior de una iglesia; se propone conquistarla y, más tarde, cuando ya es su esposa, los zapatos incentivan sus deseos eróticos y violentos. En estos casos, los zapatos se portan, su hueco se llena con el pie (falo), como si estuviéramos ante un simulacro del coito. En cambio, en Ensayo de un crimen, el zapato es un objeto aislado, un fragmento cosificado de otro (el maniquí). En este sentido, representa solo la sugerencia o la posibilidad de ser penetrado, dada la impotencia del protagonista: incapacidad tanto con Lavinia como con Carlota, pues la escena tiene lugar después del encuentro frustrado con Lavinia y antes de la próxima noche de bodas con Carlota. Esta impotencia tiene lugar en dos sentidos: la de matarlas y la de poseerlas, pues a pesar de las intenciones del personaje, con ninguna de las dos logra estos propósitos. Al comienzo de la cinta, Archibaldo niño se esconde en el armario mientras la institutriz lo busca. Al salir porta los zapatos negros de su mamá y su liguero, lo cual denota la fijación hacia la madre y su deseo de poseerla, al introducir sus pequeños pies en esos zapatos; estos representan el sexo de su madre. El fetichismo de este acto se reproduce en la vida adulta del protagonista ${ }^{27}$.

El vaso de leche es otro símbolo del incesto. Se muestra cuando Archibaldo está cerca de sus presuntas víctimas, ejemplos: en la casa de Patricia Terrazas, cuando va para matarla; también aparece en la habitación del hospital, donde persigue a la monja para asesinarla y en el bar donde se encuentra con Lavinia, aquí ordena, como es su costumbre, la misma bebida. La leche simboliza la relación incestuosa con la madre aún no superada; el personaje adulto

25 Esto también se asocia al complejo de Edipo, pues el significado de Edipo es pie hinchado o falo abultado, cuyas dimensiones impiden ajustarse a un zapato.

El diario de una recamarera (1964).

El zapato también aparece en una mesa de la casa de juego, Patricia Terrazas se quita uno de sus finos zapatos negros, lo pone sobre la mesa para mostrarlo a los hombres que están a su lado. En este contexto, el zapato constituye un ofrecimiento sexual. El negro de los zapatos, en el cine de Buñuel, puede significar la asociación del acto sexual con la muerte, tal y como lo dice en sus memorias. 
bebe leche como si fuera un niño alimentado por el seno materno ${ }^{28}$. El caso de Lavinia se vincula al erotismo, pues en el bar, con un vaso de leche sobre su mesa, la imagina envuelta en llamas, símbolo de la pasión, "como [su] Juana de Arco" quien murió quemada. Esto remite al placer erótico que denotan el rostro y los ojos del protagonista, durante la escena de las llamas que envuelven al maniquí al quemarlo en el horno ceramista de su casa, mediante primeros y primerísimos primeros planos.

Usigli no refuerza, como Buñuel, el tema del incesto y se extiende hacia otros tópicos, como lo urbano y las relaciones psicosociales de la clase burguesa, aunque el cineasta también los incluye. Carolyn Wolfenzon (citado en Quinn 52-53) piensa que en la novela, lo social incide más que lo psicológico en la conducta del personaje y argumenta que la Conquista y la Revolución son acontecimientos históricos que han influido en la manera de ser de los mexicanos ${ }^{29}$. Lo cierto es que lo social y lo psicológico nunca se disocian y que Buñuel, así como ha insistido en el tema del incesto y sus consecuentes perversiones con la influencia de la moral católica, también ha retratado el fracaso de la modernidad, las costumbres de la burguesía, sus vicios, su ideología en obras como Los olvidados (1950), El ángel exterminador (1962), Le charme discret de la bourgeoisie (1972) ${ }^{30}$, entre muchas más.

Por último, las navajas son objetos simbólicos en las dos obras y uno de los más emblemáticos en el cine de Buñuel. Sobre ellos dice Freud:

Todos los objetos alargados, bastones, troncos de árboles, sombrillas y paraguas [...] y todas las armas largas y agudas, cuchillos, puñales, picas son representaciones del órgano genital masculino (192).

Las armas y las herramientas más diversas -arados, martillos, pistolas, revólveres, puñales, sables, etc.,-- son también empleadas como símbolos del miembro masculino (194).

La navaja de afeitar en la novela, con la cual Roberto mata a su esposa de once puñaladas, en la cinta desempeña funciones similares: la de rasurar y la de ser herramienta para matar. Aunque aquí, el objeto se multiplica: una colección de navajas, como si tuviera una para cada día de la semana, lo cual acentúa la obsesión del protagonista. Sin embargo, cuando pretende asfixiar a Lavinia recurre a una toalla y al imaginar que asesina a su esposa rezando, emplea una pistola. Las navajas y las pistolas son símbolos fálicos criminales que salvaguardan el vínculo incestuoso con la madre. En la obra escrita, el protagonista recurre a objetos sin connotaciones fálicas, tales como un pisapapeles y un saco de municiones.

28 En una de las primeras secuencias de Ensayo de un crimen, sobre la mesa, en la que Archibaldo niño va a cenar, hay un vaso de leche; elemento que ayuda a reforzar que entre la vida infantil y la vida adulta de Archibaldo no se han producido cambios.

29 Wolfenson se apoya en Usigli y Octavio Paz y dice que la "herida abierta" y el ensimismamiento de la aristocracia holgazana, de la cual forma parte el protagonista, lo convirtieron en criminal.

30 El discreto encanto de la burguesía. 


\section{Reflexión final}

La proyección empática del crimen potencial e imaginativo de la película y su final feliz tienen como trasfondo la idea de que la imaginación no tiene limitaciones. La imaginación es el único espacio de libertad, en el que ni la religión, ni la ley, ni la familia pueden intervenir: la imaginación es libre, el hombre no. Esto mismo está detrás de las obras del marqués de Sade, cuyos crímenes ocurrieron en su imaginación y con los cuales sublimó sus pulsiones. Buñuel admiró a Sade y este inspiró sus obras ${ }^{31}$, las que comenzó a leer a sus 25 años en París: « ¡habrían tenido que hacerme leer a Sade antes que todas las demás cosas! ¡Cuántas lecturas inútiles!» (Buñuel 277). De ahí que, el cineasta otorgue a la imaginación un lugar de privilegio, «pese a que el cristianismo ha inventado, incluso, el pecado de intención» (Buñuel 122-224). Piensa que las fantasías, aún las más perversas, develan los deseos más oscuros y sinceros del ser humano y que el problema radica en pasar a los actos. El cineasta desprecia la hipocresía y la pornografía, privilegia el erotismo, cuyo sitio es la imaginación. En sus memorias, Buñuel afirma que en el pasado su conciencia le prohibió imágenes como asesinar a su hermano o acostarse con su madre, que rechazó de manera furiosa. Más tarde cambió: «»

Solo a los sesenta o sesenta y cinco años de edad comprendí y acepté plenamente la inocencia de mi imaginación [...], que en manera alguna se trataba de lo que se llamaba 'malos pensamientos', de 'un pecado', y que había que dejar ir a mi imaginación, aun cruenta y degenerada. (Buñuel 224).

Buñuel en su autobiografía, objeta la psicología y el psicoanálisis al parecerle disciplinas constantemente desmentidas por el comportamiento humano, inútiles para darles vida a los personajes y destinadas a las clases altas. No obstante, declara que las lecturas de Freud y el descubrimiento del inconsciente le aportaron mucho en su juventud (Buñuel 267). Se puede decir que sus experiencias de vida, sus lecturas de Freud, su sensibilidad y su formación artística coadyuvaron a la consolidación de su poética simbólica. El proceso artístico es intuitivo, pero esta intuición es producto de los factores antes mencionados. La razón, que tanto desdeñó, únicamente la empleó al momento de articular los contenidos de sus obras, al elegir los símbolos y al reconocer, mediante la autocrítica, lo que le pareció afortunado o desafortunado de las mismas.

El mérito principal de la única novela publicada por Usigli radica en que, a partir de un eje narrativo en torno al crimen, simbolizado en la caja y su música, aborda las interrelaciones de una clase social ociosa, cursi e hipócrita, sus costumbres y su moral, cuyas implicaciones desembocan en la perversión y el crimen. Esta obra inaugura la novela negra en México; su exitoso manejo del suspenso atrapa a los lectores en una recreación social y psicológica en el ambiente urbano de la Ciudad de México descrito con detalle. El tema es el crimen artístico perfecto, fantasía que Roberto desea transformar en realidad, aunque, paradójicamente, plantea que tal perfección no existe, porque implica su desconocimiento, lo cual oculta la celebridad del criminal. La trama, a la vez, pone en tela de juicio la injusticia, la

31 Por ejemplo, en Nazarín, la escena con el moribundo se inspiró en Diálogo de un sacerdote y un moribundo de Sade (Buñuel, 2012, 274). 
incapacidad y la falta de criterio para develar la psicología criminal. El análisis comparativo de las relaciones espacio temporales entre la novela y la película confirma que el diálogo entre cine y literatura sigue variados caminos. Por último y a pesar de la riqueza simbólica del cine de Buñuel, conviene decir que las actuaciones en la cinta estudiada demeritan la calidad del producto, debido al tono afectado y artificial de algunos personajes.

\section{REFERENCIAS}

Bakhtine, Mikhaïl. Esthétique et théorie du roman. Paris, Gallimard, 2016. Impreso.

Buñuel, Luis. Mi último suspiro. México D.F., Debolsillo, 2012. Impreso.

Burke, Edmund. De lo sublime y de lo bello. Indagación filosófica sobre el origen de nuestras ideas acerca de lo sublime y de lo bello. Madrid, Alianza Editorial, 2014. Impreso.

De Quincey, Thomas. Del asesinato considerado como una de las Bellas Artes. México D.F., Lectorum, 2007. Impreso.

Freud, Sigmund. La interpretación de los sueños (2). Madrid, Alianza editorial, 1987. Impreso.

Genette, Gerard. Figuras III. Barcelona, Lumen. 1989. Impreso.

Hegel, Georg . Estética. Sistema de las artes. Buenos Aires, Ediciones Liberador, 2006. Impreso.

Herrera, Javier. Luis Buñuel en su archivo. De Los olvidados a Viridiana. Madrid, Fondo de Cultura Económica, 2015. Impreso.

Hugo, Víctor. Cromwell. Madrid, Espasa Calpe, 1967. Impreso.

Jauss, Hans Robert. Pequeña apología de la experiencia estética. Barcelona, Ediciones Paidós, 2002. Impreso.

Kant, Immanuel. Lo bello y lo sublime. Fundamentación de la metafisica de las costumbres. México D.F, Tomo Clásicos, 2004. Impreso.

Kracauer, Siegfried. Teoría del cine. La redención de la realidad física. Barcelona, Paidós Comunicación Cine, 2015. Impreso.

Kurnitzky, Horst. Edipo. Un héroe del mundo occidental. Trad. Celia Bulit, México D.F., Siglo XXI editores, 1992. Impreso.

Lessing, Gotthold Ephraim. Laocoonte. Madrid, Editorial Tecnos, 2015. Impreso.

Monegal, Antonio. Luis Buñuel, de la literatura al cine. Una poética del objeto. Madrid, Anthropos, 1993. Impreso. 
Nietzsche, Friedrich. El nacimiento de la tragedia o Grecia y el pesimismo. Madrid Alianza Editorial, 2014. Impreso.

Paz, Octavio. La llama doble. Amor y erotismo. Barcelona, Seix Barral, 1993. Impreso.

Quinn, Paul Patrick «Ensayo De Un Crimen». De La página a La Pantalla. Fotocinema. Revista Cientifica De Cine Y Fotografía, n. ${ }^{\circ}$ 14, diciembre de 2017, 43-57, doi:10.24310/ Fotocinema.2017.v0i14.3572.

Rosenkranz, Karl. Estética de lo feo. Madrid, Julio Ollero Editor, 1992. Impreso.

Stam, Robert. Teoría y práctica de la adaptación. Trad. Florencia Talavera. México D.F., Universidad Nacional Autónoma de México, 2014. Impreso.

Usigli, Rodolfo. Ensayo de un crimen. México D.F., Debolsillo, 2018. Impreso.

\section{FILMOGRAFÍA}

Viridiana. Dir. Luis Buñuel. Unión Industrial Cinematográfica (uninci), 1961. DVD.

El ángel exterminador. Dir. Luis Buñuel. México, Producciones Gustavo Alatriste, 1962. DVD.

Nazarín. Dir. Luis Buñuel. México, Producciones Barbachano Ponce, 1959. DVD.

Une chien andalou. Dir. Luis Buñuel. Buñuel, 1929. DVD.

Los olvidados. Dir. Luis Buñuel. Ultramar Films, 1950. DVD.

La mort en ce jardin. Dir. Luis Buñuel. Ultramar Films, 1956. DVD.

Belle de jour. Dir. Luis Buñuel. Paris Film Productions, 1967. DVD.

Ensayo de un crimen. Dir. Luis Buñuel. Alianza Cinematográfica Española, 1955. DVD.

Le journal d'une femme de chambre. Dir. Luis Buñuel. Speva, Filmalliance, Film Sonor, Dear Film, 1964. DVD.

Le charme discret de la bourgeoisie. Dir. Luis Buñuel. Film Productions, Jet Films, Dean Films, 1972. DVD.

Cet obscur objet du désir. Dir. Luis Buñuel. Greenwich Film Productions, Les Films Galaxie, In Cine Compañia Industrial Cinematográfica. 1977. DVD. 